\section{Clinical implications}

- Tinea pedis (athlete's foot) occurs in about $15 \%$ of the population

- Its usual treatment is a topical antifungal applied two or three times a day for up to four weeks

- Terbinafine is a synthetic allylamine antifungal with a primarily fungicidal action against dermatophytes and some other moulds and yeasts

- This study shows that terbinafine $1 \%$ cream applied twice daily for a week was significantly more effective in treating tinea pedis than a four week course of clotrimazole $1 \%$ cream, both clinically and mycologically

- Because it has a high efficacy in the short term terbinafine may become the preferred topical treatment for tinea pedis

bility that the use of placebo cream for three weeks after active treatment in the terbinafine group (to make the study double blind) may have in some way enhanced the cure rate, although any such effect is likely to have been minimal.

A new topical antifungal agent needing fewer applications and a shorter duration of treatment would clearly be advantageous and likely to improve compliance by patients provided that efficacy is not compromised. Results to date have shown that reducing the duration of treatment with terbinafine $1 \%$ cream to one week in tinea infections does not compromise efficacy. ${ }^{5-9}$ This study further confirms these findings but more importantly shows that one week's terbinafine $1 \%$ cream is actually significantly more effective than the recommended four weeks' treatment with clotrimazole $1 \%$ cream in tinea pedis. The cost implications are that one week's treatment with terbinafine $1 \%$ cream costs $£ 4.98$ (15 g tube) compared with $£ 4.26$ for four weeks' treatment with clotrimazole $1 \%$ cream ( $50 \mathrm{~g}$ tube). Possibly terbinafine $1 \%$ cream will become the preferred topical treatment of tinea pedis.

We thank the following colleagues for their contribution to the study and for allowing us to use their data: R C Goodfellow, Preston; R D Rowley and S Gibeon, London; A Bevan, Potters Bar; R Cranfield and R J Baldwin, Gwent; R B Lamberton, Aberdeen; J P Heatley, Horsham; R Cantor, C A Maxwell, and D M Entwistle, Cardiff; R C Joshipura, S K Chouksey, J M Shah, and C S Joshipura, Manchester; A K Mishra, Lancashire; K Brown, Coppull; R Thrush, Walsall; J Adams, T J Mallon, and R N Stones, Cheshire; P M Baldwin, Nottingham; H MacKinnon and J R Ross, Glasgow; R A J Seaman, Hitchin; P C Heaney, Northampton; G J Brown, Birmingham; I G V James, Bolton; B K Jaiswal, Essex; T F Poyner, Cleveland. We thank Mr R A Forster for help with the mycological investigations and Sandoz Pharmaceuticals (UK) for supplying the terbinafine and supporting the study.

1 Sud IJ, Fenigold DS. Mechanisms of action of the antimycotic imidazoles. f Invest Dermatol 1981;76:438-41.

2 Petranyi G, Meingassner JG, Meith $\mathrm{H}$. Antifungal activity of the allylamine derivative terbinafine in vitro. Antimicrob Agents Chemother 1987;31:1365-8.

3 Clayton YM. In vitro activity of terbinafine. Clin Exp Dermatol 1989;14:101-4.

4 Villars V, Jones TC. Clinical efficacy and tolerability of terbinafine (Lamisil) a new topical and systemic fungicidal drug for treatment of dermatomycoses. Clin Exp Dermatol 1989;14:124-7.

5 Millikan LE. Efficacy and tolerability of topical terbinafine on the treatment of tinea cruris. 7 Am Acad Dermatol 1990;23:795-9.

6 Greer DL, Jolly HW Jr. Treatment of tinea cruris with topical terbinafine. IAm Acad Dermatol 1990;23:800-4.

7 Evans EGV, James IGV, Joshipura RC. One week treatment of tinea corporis and tinea cruris with terbinafine (Lamisil) $1 \%$ cream: a placebo controlled study. Fournal of Dermatological Treatment 1992;3:181-4.

8 Evans EGV, James IGV, Joshipura RC. Two week treatment of tinea pedis with terbinafine (Lamisil) 1\% cream: a placebo-controlled study. foumal of Dermatological Treatment 1991;2:95-7.

9 Berman B, Ellis C, Leydon J, Lowe N, Savin R, Shupack J, et al. Efficacy of a 1 week, twice daily regimen of terbinafine $1 \%$ cream in the treatment of interdigital tinea pedis. $f$ Am Acad Dermatol 1992;26:956-60.

10 Hill S, Thomas R, Smith SG, Finlay AY. An investigation of the pharmacokinetics of topical terbinafine (Lamisil) 1\% cream. Br $\mathcal{F}$ Dermatol 1992;127: $396-400$

11 Evans EGV. A double-blind comparison of 1, 3, 5 and 7 day topical therapy with $1 \%$ terbinafine (Lamisil) cream in tinea pedis. $\mathrm{Br} \mathcal{f}$ Dermatol 1992;127:21.

(Accepted 22 fune 1993)

\title{
Psychiatric consequences of road traffic accidents
}

\author{
Richard Mayou, Bridget Bryant, Robert Duthie
}

Abstract

Objective-To determine the psychiatric consequences of being a road traffic accident victim.

Design-Follow up study of road accident victims for up to one year.

Setting-Emergency department of the John Radcliffe Hospital, Oxford.

Subjects-188 consecutive road accident victims

University Department of Psychiatry, Warneford Hospital, Oxford OX3 7JX Richard Mayou, clinical reader in psychiatry Bridget Bryant, research officer

Nuffield Department of Orthopaedic Surgery, Nuffield Orthopaedic Centre, Oxford

Robert Duthie, professor

Correspondence to:

Dr Mayou.

BM于 1993;307:647-51 aged 18-70 with multiple injuries (motorcycle or car) or whiplash neck injury, who had not been unconscious for more than 15 minutes, and who lived in the catchment area.

Main outcome measures-Present state examination "caseness"; post-traumatic stress disorder and travel anxiety; effects on driving and on being a passenger.

Results-Acute, moderately severe emotional distress was common. Almost one fifth of subjects, however, suffered from an acute stress syndrome characterised by mood disturbance and horrific memories of the accident. Anxiety and depression usually improved over the 12 months, though one tenth of patients had mood disorders at one year. In addition, specific post-traumatic symptoms were common. Post-traumatic stress disorder occurred during follow up in one tenth of patients, and phobic travel anxiety as a driver or passenger was more common and frequently disabling. Emotional disorder was associated with having pre-accident psychological or social problems and, in patients with multiple injuries, continuing medical complications. Post-traumatic syndromes were not associated with a neurotic predisposition but were strongly associated with horrific memories of the accident. They did not occur in subjects who had been briefly unconscious and were amnesic for the accident. Mental state at three months was highly predictive of mental state at one year.

Conclusions-Psychiatric symptoms and disorder are frequent after major and less severe road accident injury. Post-traumatic symptoms are common and disabling. Early information and advice might reduce psychological distress and travel anxiety and contribute to road safety and assessing "nervous shock."

\section{Introduction}

Road traffic accidents are a major cause of morbidity and are the main cause of death in people under 30 . 
Little is known about the detailed consequences for mental state or other aspects of quality of life but they are believed to be considerable. ${ }^{1}$ A postal survey (response rate $30 \%$ ) in Ontario three to four years after a road accident suggested that psychiatric problems were common and noted a fear of driving in $18 \%$ of respondents. Case reports ${ }^{2}$ and general population surveys indicate ${ }^{3-5}$ that post-traumatic stress disorder (intrusive memories, avoidance, distress) occurs in a minority of road traffic accident victims, and we have reported a postal survey showing that anxiety about travel-both as a driver and as a passenger-is frequent five to six years after injury. ${ }^{6}$ There are also many, largely retrospective reports of "compensation neurosis" in highly selected groups of litigants. ${ }^{7}$ This issue is particularly controversial in relation to whiplash neck injury. ${ }^{8}$

There has been only one prospective study of road accident victims, ${ }^{9}$ although there have been general accounts of mixed groups of accident victims suffering a wide range of injuries in all forms of accident. ${ }^{111}$ This paper is part of a continuing programme of prospective research and describes (a) the psychiatric consequences in three representative groups of road traffic accident victims; (b) the associations between psychiatric morbidity, physical impairment, and disability; and $(c)$ the early predictors of poor psychiatric outcome.

\section{Subjects and methods}

This study was part of the Oxford Road Accident Group research programme, in which medical and accident information is obtained on all road traffic accident victims attending the emergency department at the John Radcliffe Hospital, Oxford. ${ }^{12}$ We identified all subjects aged 18-70 and living in the city or county of Oxfordshire within three clinical groups chosen as examples of major and minor injury and of two types of vehicle accident: (a) multiple injury victims (abbreviated injury score ${ }^{13} 3$ or more, or 2 if injury was to more than one body area) who had been car or other vehicle occupants; $(b)$ multiple injury victims who had been motorcycle drivers or passengers; $(c)$ whiplash injury victims who had no other physical injury. Those with head injuries resulting in unconsciousness for more than 15 minutes were excluded.

Patients in the first two categories were assessed by the Oxford Road Accident Group, who collected standardised information about the accident and injuries and management in hospital. Patients in the whiplash injury group were identified by review of accident department records. Altogether 200 patients met the inclusion criteria: 55 car occupants, 71 motorcyclists, and 74 whiplash injury victims. One car occupant and seven whiplash injury victims refused the study, and four patients in the whiplash injury group had given false addresses so could not be traced.

Multiple injury victims were initially interviewed in hospital as soon as they were fit enough (vehicle occupants mean 8.5 (range 2-26) days, motorcyclists mean 9.5 (range 1-41) days). Whiplash injury victims were contacted at home and interviewed as soon as possible (mean 25.4 (range 8-54) days). Subjects were interviewed again at three months (at home or at the outpatient department) and one year. Two, both car occupants, died during follow up (one of unexpected complications of his injuries, one of cancer); eight withdrew (one car occupant, four motorcycle riders, three whiplash injury victims); and seven moved away and were untraceable (two car occupants, two motorcycle riders, three whiplash injury victims). Complete data were therefore available at one year for 171 subjects.

The following variables were assessed at baseline: demographic; nature of the accident; social adjustment in the month before the accident (semistructured interview covering psychiatric symptoms, work, leisure, family life, social life, and financial circumstances); previous driving behaviour; psychological self report questions (Eysenck personality inventory ${ }^{14}$ and two measures of current mood-Beck depression inventory ${ }^{15}$ and Spielberger anxiety scale $^{16}$ ); and the present state examination (a standardised semistructured clinical interview covering the month before the accident). ${ }^{17}$ Additional information was obtained from medical notes and police and ambulance reports. Severity of injury was rated by the abbreviated injury score and injury severity score. ${ }^{13}$

At three months and one year the baseline measures were repeated. A semistructured interview covered current medical symptoms, use of medical services and disability, changes in driving behaviour and concern about travel (driver and passenger), litigation (prosecution and compensation proceedings), and the symptoms of post-traumatic stress disorder (DSM-III-R). ${ }^{18}$ A rating of medical outcome was made for the multiple injury groups from the hospital records. The four point scale was defined to range from no impairment to physical symptoms or disability causing major restriction of function. Subjects in the whiplash injury group, who suffered much less severe medical problems and were not seen again as outpatients, could not be rated.

Statistical analysis was by $\chi^{2}$ and Fisher's exact tests. Canonical correlation analysis ${ }^{19}{ }^{20}$ was used to model the relations between dependent variables (psychiatric outcomes) and explanatory variables. Extensive pre-

TABLE I-Characteristics of subjects. Except where stated otherwise figures are numbers (percentages) of subjects

\begin{tabular}{|c|c|c|c|}
\hline & $\begin{array}{c}\text { Car } \\
\text { occupants }\end{array}$ & $\begin{array}{l}\text { Motorcycle } \\
\text { riders }\end{array}$ & $\begin{array}{l}\text { Whiplash } \\
\text { injury victims }\end{array}$ \\
\hline Met criteria & 55 & 71 & 74 \\
\hline \multicolumn{4}{|l|}{ Interviewed: } \\
\hline Baseline & 54 & 71 & 63 \\
\hline 3 Months & 49 & 64 & 61 \\
\hline 1 Year & 49 & 65 & 57 \\
\hline Mean age (years) (SD) & $31 \cdot 4(12.0)$ & $28.6(12 \cdot 8)$ & $30 \cdot 8(11 \cdot 1)$ \\
\hline Male & $39(72)$ & $62(87)$ & $27(43)$ \\
\hline Female & $15(28)$ & $9(13)$ & $36(57)$ \\
\hline \multicolumn{4}{|l|}{ Marital status: } \\
\hline Single & $23(43)$ & $44(62)$ & $30(48)$ \\
\hline Married/cohabiting & $30(56)$ & $21(30)$ & $30(48)$ \\
\hline $\begin{array}{l}\text { Widowed/divorced/ } \\
\text { separated }\end{array}$ & $1(2)$ & $6(8)$ & $3(5)$ \\
\hline \multicolumn{4}{|l|}{ Social class: } \\
\hline I & $4(7)$ & $1(1)$ & $5(8)$ \\
\hline II & $13(24)$ & $13(18)$ & $13(21)$ \\
\hline III NM* & $7(13)$ & $6(8)$ & $21(33)$ \\
\hline III $\mathbf{M}^{\star}$ & $21(39)$ & $26(37)$ & $15(24)$ \\
\hline IV & $8(15)$ & $17(24)$ & $9(14)$ \\
\hline $\mathrm{V}$ & $1(2)$ & $8(11)$ & $0(0)$ \\
\hline \multicolumn{4}{|l|}{ Mean abbreviated injury } \\
\hline score (SD) & $2.98(0.4)$ & $3.03(0.4)$ & - \\
\hline \multicolumn{4}{|l|}{ Mean injury severity score } \\
\hline Driver & $46(85)$ & $66(93)$ & $49(78)$ \\
\hline Passenger & $8(15)$ & $5(7)$ & $14(22)$ \\
\hline \multicolumn{4}{|l|}{ Previous accidents: } \\
\hline 0 & $36(67)$ & $28(39)$ & $42(67)$ \\
\hline 1 & $13(24)$ & $32(45)$ & $16(25)$ \\
\hline$\geqslant 2$ & $5(9)$ & $11(15)$ & $5(8)$ \\
\hline \multicolumn{4}{|c|}{ Previous road traffic accident injury: } \\
\hline Nil & $45(83)$ & $40(56)$ & $54(86)$ \\
\hline Minor & $4(7)$ & $16(23)$ & $6(10)$ \\
\hline Major & $5(9)$ & $15(21)$ & $3(5)$ \\
\hline \multicolumn{4}{|l|}{ Memory of accident: } \\
\hline No & $26(48)$ & $16(23)$ & $2(3)$ \\
\hline Yes, not frightening & $12(22)$ & $36(51)$ & $39(62)$ \\
\hline Yes, "horrific" & $16(30)$ & $19(27)$ & $22(35)$ \\
\hline \multicolumn{4}{|l|}{ Fault (interviewer rating): } \\
\hline Not at fault & $14(29)$ & $30(44)$ & $46(94)$ \\
\hline Probably at fault & $22(46)$ & $30(44)$ & $2(4)$ \\
\hline Not known & $12(25)$ & $8(12)$ & $1(2)$ \\
\hline N/At (not in charge of & & 3 & 1 \\
\hline \multicolumn{4}{|c|}{$\begin{array}{l}\text { vehicle) } \\
\text { Medical outcome at } 1 \text { year (hospital notes): }\end{array}$} \\
\hline Very poor & $3(6)$ & $5(8)$ & N/At \\
\hline Poor & $8(16)$ & $15(23)$ & N/A \\
\hline Fair & $17(35)$ & $25(38)$ & N/A \\
\hline Good & $21(43)$ & $20(31)$ & N/A \\
\hline
\end{tabular}

${ }^{\star} \mathrm{NM}=$ Non-manual. $M$ - Manual.

$\dagger \mathrm{N} / \mathrm{A}=$ Not applicable. 
liminary analysis allowed a choice of eight baseline explanatory variables relating to the type of accident, sex, age, injury severity, previous psychological problems, neuroticism, years of driving, and memories of the accident.

\section{Results}

The 188 respondents at baseline interview had been involved in 184 accidents. Three pairs in the study had been in the same vehicle, and one pair were drivers of cars which collided. Two thirds of the respondents were travelling alone, and a fifth were in accidents in which someone else in their vehicle was injured or, in three cases, killed. Characteristics of the subjects are shown in table I. Mean ages were similar in the three groups. Motorcyclists, however, were more likely to be male, single, and unemployed; to be of lower social class; and to report drinking problems. They also suffered more disabling physical injuries (mainly leg fractures) and were more likely to have had previous accident injury.

TABLE II-Psychiatric complications. Figures are numbers (percentages) of subjects interviewed at each stage

\begin{tabular}{lccc}
\hline & $\begin{array}{c}\text { Car } \\
\text { occupants }\end{array}$ & $\begin{array}{c}\text { Motorcycle } \\
\text { riders }\end{array}$ & $\begin{array}{c}\text { Whiplash } \\
\text { injury victims }\end{array}$ \\
\hline $\begin{array}{l}\text { Present state examination "case": } \\
\quad \text { Before accident }\end{array}$ & $0 / 54$ & $1 / 71(1)$ & $0 / 63$ \\
3 Months & $4 / 49(8)$ & $10 / 64(6)$ & $11 / 61(18)$ \\
$\quad$ 1 Year & $4 / 49(8)$ & $9 / 65(14)$ & $7 / 57(12)$ \\
Post-traumatic stress disorders: & & & \\
$\quad$ 3 Months & $4 / 49(8)$ & $6 / 64(9)$ & $4 / 61(7)$ \\
1 Year & $3 / 49(6)$ & $7 / 65(11)$ & $3 / 57(5)$ \\
Travel anxiety: & & & \\
$\quad$ Months & $12 / 49(24)$ & $7 / 64(11)$ & $13 / 61(21)$ \\
1 Year & $6 / 49(12)$ & $10 / 65(15)$ & $10 / 57(18)$ \\
\hline
\end{tabular}

TABLE II-Social and medical factors by psychiatric complications at one year

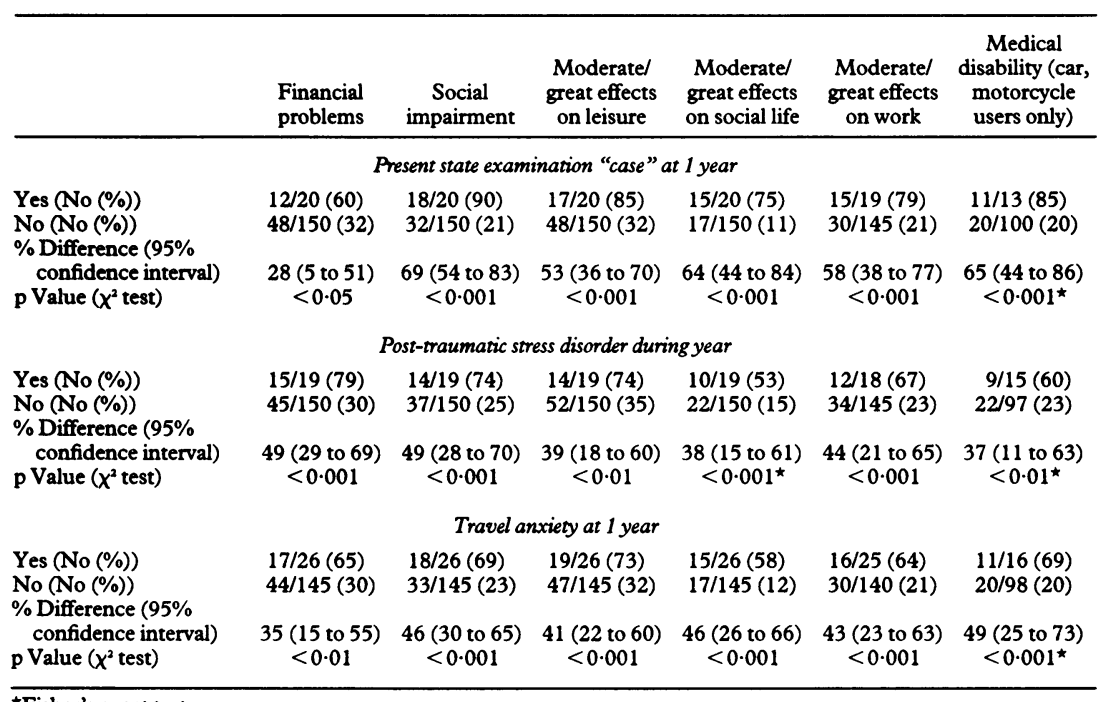

^Fisher's exact test.

TABLE IV-Intrusive thoughts of accident. Figures are numbers (percentages) of subjects interviewed at each stage

\begin{tabular}{lcccc}
\hline & $\begin{array}{c}\text { Car } \\
\text { occupants }\end{array}$ & $\begin{array}{c}\text { Motorcycle } \\
\text { riders }\end{array}$ & $\begin{array}{c}\text { Whiplash } \\
\text { injury victims }\end{array}$ & Total \\
\hline After accident: & & & & \\
$\quad$ No & $26 / 54(48)$ & $16 / 71(23)$ & $2 / 63(3)$ & $44 / 188(23)$ \\
Yes, not frightening & $12 / 54(22)$ & $36 / 71(51)$ & $39 / 63(62)$ & $87 / 188(46)$ \\
Yes, "horrific" & $16 / 54(30)$ & $19 / 71(27)$ & $22 / 63(35)$ & $57 / 188(30)$ \\
3 Months: & & & & \\
$\quad$ No & $34 / 49(69)$ & $48 / 64(75)$ & $48 / 61(79)$ & $130 / 174(75)$ \\
Yes, not frightening & $11 / 49(22)$ & $10 / 64(16)$ & $9 / 61(15)$ & $30 / 174(17)$ \\
Yes "horrific" & $4 / 49(8)$ & $6 / 64(9)$ & $4 / 61(7)$ & $14 / 174(8)$ \\
1 Year: & $32 / 49(65)$ & $52 / 65(80)$ & $46 / 57(81)$ & $130 / 171(76)$ \\
No & $14 / 49(29)$ & $6 / 65(9)$ & $8 / 57(14)$ & $28 / 171(16)$ \\
Yes, not frightening & $3 / 49(6)$ & $7 / 65(11)$ & $3 / 57(5)$ & $13 / 171(8)$ \\
Yes "horrific" & & & & \\
\hline
\end{tabular}

ACUTE DISTRESS

At the first assessment emotional distress was usually of moderate intensity, but 77 (41\%) subjects, especially those with multiple injuries, reported anxiety or depression above the usually accepted thresholds for clinical disorder-that is, a score of 40 on the Spielberger anxiety scale and 4 on the short version Beck depression self report scale. Subjects who accepted that they had been responsible for the accident showed little distress or guilt during the interview about the injury or even death of others.

Thirty one subjects (18\%) described an acute distress syndrome characterised by anxiety or depression above the normal range together with "horrific" intrusive memories of the accident. The occurrence of acute distress was not associated with age, sex, or type of accident or of accepting blame for the accident, but it was significantly associated with neuroticism (difference $28 \%$ ( $95 \%$ confidence interval 10 to 46 ); $p<0.01$ ) and not being unconscious (difference $23 \%$ (10 to 36 ); $\mathrm{p}<0.05)$ after the accident. These 31 subjects had a poor psychological outcome at one year, only five reporting no persistent psychiatric complications. Thirteen suffered present state examination mood disorder (anxiety or depression), 13 phobic travel anxiety, and nine post-traumatic stress disorder.

\section{EMOTIONAL DISTRESS DURING FOLLOW UP}

Mean self report anxiety and depression scores decreased during follow up (data not shown). Throughout, distress was most severe in the motorcyclists and least severe in subjects with whiplash injury. Motorcyclists also reported more social and financial difficulties during the year. Most subjects reported a good psychological outcome at one year, but the present state examination classified a tenth of subjects as "cases" of mood disorder, a proportion twice that expected in the general population and substantially higher than in the month before the accident (table II). The commonest psychiatric diagnosis recorded with the present state examination CATEGO program was anxiety disorder. There was considerable continuity in emotional distress between three and 12 months, no cases at 12 months being recorded in subjects who had not suffered psychiatric disorder at three months. Psychiatric disorder at one year was associated (table III) with continuing medical problems and with all types of social problems (work, leisure, and financial).

\section{POST-TRAUMATIC SYNDROMES}

In addition to the symptoms of anxiety and depression, which were similar in frequency to those occurring after major physical disorder, two specific but overlapping syndromes of post-traumatic psychological distress were frequent.

Post-traumatic stress disorder-Many subjects with multiple injuries had suffered brief unconsciousness and could not remember the accident (table I), but in the remainder memories of the accident were commonly reported throughout the follow up year (table IV). Roughly a third of patients recalled the accident as "horrific" at the baseline interview. During the year after the accident 19 subjects (11\%) satisfied DSMII-R criteria ${ }^{21}$ for post-traumatic stress disorder-that is, intrusive thoughts of the trauma, avoidance, and emotional arousal. Eight subjects suffered posttraumatic stress disorder at three and 12 months, five at three months only, and six at 12 months only.

Concern about travel-Changes in driving behaviour, such as driving more cautiously, being more alert to other road users' behaviour, and changing to a safer vehicle, were common and will be reported elsewhere. Concern about travel was also frequent, both as a driver and as a passenger (table V). Though sometimes 
TABLE V-Concerm about driving and being a passenger. Figures are numbers (percentages) of subjects

\begin{tabular}{|c|c|c|c|}
\hline & $\begin{array}{c}\text { Car } \\
\text { occupants }\end{array}$ & $\begin{array}{l}\text { Motorcycle } \\
\text { riders }\end{array}$ & $\begin{array}{l}\text { Whiplash } \\
\text { injury victims }\end{array}$ \\
\hline \multicolumn{4}{|c|}{ Effects on driving * } \\
\hline \multicolumn{4}{|l|}{3 Months: } \\
\hline Nil & $7 / 31(23)$ & $3 / 25(12)$ & $20 / 57$ (35) \\
\hline Minor & $18 / 31(58)$ & $3 / 25(12)$ & $23 / 57(40)$ \\
\hline Major & $6 / 31(19)$ & $19 / 25(76)$ & $14 / 57(25)$ \\
\hline Not able yet & 16 & 37 & 2 \\
\hline Does not drive & 2 & 2 & 2 \\
\hline \multicolumn{4}{|l|}{1 Year: } \\
\hline Nil & $18 / 44(41)$ & 7/53(13) & $22 / 55(40)$ \\
\hline Minor & $21 / 44(48)$ & $17 / 53(32)$ & $21 / 55$ (38) \\
\hline Major & $5 / 44(11)$ & $29 / 53(55)$ & $12 / 55(22)$ \\
\hline Not able yet & 3 & 10 & 0 \\
\hline Does not drive & 2 & 2 & 2 \\
\hline \multicolumn{4}{|c|}{ Effects on being a passengert } \\
\hline \multicolumn{4}{|l|}{3 Months: } \\
\hline Nil & $17 / 49(35)$ & $32 / 64(50)$ & $20 / 61$ (33) \\
\hline Minor & $21 / 49$ & $22 / 64(34)$ & $31 / 61(51)$ \\
\hline Major & $11 / 49(22)$ & $10 / 64(16)$ & $10 / 61(16)$ \\
\hline \multicolumn{4}{|l|}{1 Year: } \\
\hline Nil & $24 / 49$ (49) & $30 / 65(46)$ & $26 / 57(46)$ \\
\hline Minor & $71 / 49(35)$ & $23 / 65$ (35) & $19 / 57$ (33) \\
\hline Major & $8 / 49(16)$ & $12 / 65(18)$ & $12 / 57(21)$ \\
\hline
\end{tabular}

*Driving a car for car and whiplash injury groups, driving a motorbike for motorcycle group. Figures are numbers (percentages) of those fit enough to drive at each stage.

†Passenger in a car. Figures are numbers (percentages) of those fit enough to drive at each stage.

minor and transient, concern was in many instances severe and persistent at one year, limiting the extent of travel and affecting work and social and leisure activities. Subjects gave dramatic accounts of anxiety and panic attacks. Avoidance of travel, and particularly of the site of the accident, and anxiety about situations similar to the accident were commonly reported. In a few subjects fear of travel was so great as to limit use of public transport. Others reported considerably increased concern about relatives when they were known to be travelling. Concern about travel changed very little between three and 12 months. At one year worry about travel was severe enough in 26 subjects to satisfy the present state examination criteria for phobic anxiety. We refer to this syndrome as "travel anxiety."

\section{PATTERNS OF OUTCOME}

Almost a quarter (37) of subjects described psychiatric problems at one year, but there was a wide range of symptom patterns. The figure shows the relations among the three types of persistent psychiatric complication. All three syndromes were significantly associated (table III) with our global rating of social impairment and with specific measures of quality of life (work, leisure, social, and financial). In subjects with multiple injuries all the psychiatric consequences were significantly associated with persistent medical disability at one year. However, present state examination emotional disorder, post-traumatic stress disorder, and phobic travel anxiety were also frequent in the whiplash injury group.

Multivariate analysis (canonical correlation) showed differences in baseline predictive factors for the three types of later psychiatric outcome. These findings will be detailed elsewhere. Present state examination mood disorder at one year was predicted by evidence of previous vulnerability to psychological problems (previous psychiatric problems, neuroticism, and initial distress). The association of neuroticism with psychiatric disorder was strongest in the whiplash injury group. In contrast, post-traumatic stress disorder was not associated with neuroticism, previous psychological problems, or baseline depression. The principal and very strong predictor was the rating of "horrific" intrusive memories at the post-accident interview. It did not occur in any subject who suffered brief unconsciousness after the accident. Predictors of phobic travel anxiety were similar to those of posttraumatic stress disorder. Responsibility for the accident (self rating and interviewer's assessments), being trapped, and being embroiled in compensation proceedings did not predict any aspect of psychological outcome.

\section{Discussion}

This first systematic prospective study of the psychological impact of road accident injury disclosed major psychiatric consequences in three representative subgroups of road accident victims who escaped head injury. These were substantial and often persistent, both in those with multiple injuries and in those with whiplash neck injury. The extent, pattern, and relevance of such consequences have previously been greatly underestimated. We believe that the findings from our sample with respect to major multiple injuries and less severe whiplash injuries are applicable to the whole range of road accident victims ${ }^{12}$ and possibly also to those who escape injury.

Though acute distress was usually of moderate intensity and transient, $18 \%$ of subjects (31/171) described an acute syndrome of emotional distress together with horrific memories of the accident which would fulfil the suggested criteria of the new international classification ICD- $10^{22}$ and the draft equivalent DSM-IV ${ }^{21}$ category of acute stress reaction. This syndrome had a poor prognosis and was associated with previous psychological vulnerability (neuroticism) and remaining conscious after the accident.

Almost a quarter of subjects described psychiatric complications at one year. The extent and pattern of the continuing emotional distress were similar to those described after other medical conditions, and at one year the prevalence of the disorder was over twice that expected in the general population. It was particularly likely in those psychologically and socially vulnerable, but was also strongly associated with chronic medical impairment and social, financial, and work problems at one year. Motorcyclists suffered more psychiatric disorder than other groups, which was probably owing to their more disabling physical injuries and greater social vulnerability (lower social class; greater work, financial, and other problems; more drinking problems). However, subjects with whiplash injury described very similar problems to those with more severe physical injury. This may partly reflect selective consultation (the whiplash injury subjects scored significantly higher on the neurotic scale of the Eysneck personality inventory) but also the much higher proportion recalling the circumstances of the accident, as none were unconscious.

The considerable prevalence and impact of the two overlapping post-traumatic psychiatric syndromes, phobic travel anxiety and post-traumatic stress disorder, have not previously been described in any series of road accident victims. It is probable that road accidents are the commonest cause of such symptoms in the general population and therefore of much greater clinical relevance than symptoms after major disaster. ${ }^{23}$ Not only were post-traumatic symptoms common but they were associated with very considerably impaired quality of life, impairment which was often prolonged and disabling. In a recent postal questionnaire survey of a previous cohort of road accident victims we found that phobic travel anxiety is often remarkably persistent. $^{6}$

Despite the pronounced overlap among general emotional distress, phobic anxiety, and post-traumatic stress disorder (figure), the differences in associations with baseline predictors indicate differences in aetiology. Post-traumatic symptoms were unrelated to evidence of past emotional problems whereas anxiety 


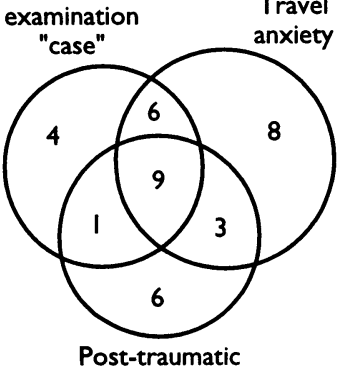

Post-traumatic stress disorder

Psychiatric comorbidity in year after road accident. Figures are numbers of subjects satisfying present state examination criteria for mood disorder ("case") or phobic travel anxiety at one year and with post-traumatic stress disorder at any stage in follow up year and depression were closely related. However, posttraumatic stress disorder and travel anxiety were strongly predicted by initial "horrific" and intrusive memories of the accident. The prospect of compensation did not predict psychiatric disorder. These findings have implications for understanding the aetiology $y^{23}$ of traumatic psychological symptoms and disorder. Plainly, neither emotional distress nor posttraumatic symptoms should be seen as "accident neurosis," a term frequently used to describe alleged exaggeration of pain or malingering in highly selected series of litigants but uncommon in our representative sample.

Our findings show that the psychological consequences of road accidents are a major clinical problem with important social, economic, and health service implications. Though in subjects with multiple injuries there was an association between posttraumatic symptoms and medical outcome, the substantial handicaps reported by the whiplash injury group emphasise the need to be aware of the possible psychological consequences not only for those who are severely injured but also for the very many people who suffer minor injury, and indeed for those who are uninjured. It should be possible to identify many of those who are at risk of long term psychological problems soon after the road accident. Those who are briefly unconscious and therefore amnesic are at low risk, but initial horrifying memories of the accident and evidence of a vulnerable personality are indicators of later difficulty. In this series subjects with problems at three months were likely to describe continuing problems at one year. Many of the psychosocial complications seem potentially preventable or treatable. Possibly, post-traumatic symptoms could be prevented or at least reduced by an early information sheet together with discussion of feelings and of the methods of coping with symptoms. In addition, mental state should be reviewed during follow up by the general practitioner and the outpatient clinic. Some people need extra social help; others with either severe immediate distress or difficulties during convalescence would benefit from specific psychiatric or psychological interventions. Travel anxiety could often be expected to respond to proved behavioural methods. It is also apparent that driving behaviour frequently changes appreciably after a road accident and that road accident injury is an important opportunity for measures to encourage safer driving.

We are grateful to Clare Passingham and members of the Oxford Road Accident Group for their help (John Threlfall, Philippa Hewer, Gerry McCoy, Gary Windler) and also to Matthew Eagle and Francis Mariott, of the department of statistics at Oxford University.

1 Raffle PAB. The cost of traffic casualties to the community. $f R S o c M e d$ 1991;84:390-2.

Kuch K, Swinson RP, Kirby M. Post-traumatic stress disorder after car accidents. Can F Psychiatry 1985;30:426-7.

3 Norris FH. Epidemiology of trauma: frequency and impact of differen potentially traumatic events on different demographic groups. $f$ Consut Clin Psychol 1992;60:409-18.

\section{Clinical implications}

- One fifth of road accident victims with major or minor injuries report severe initial distress characterised by altered mood and horrific memories

- A quarter describe long term psychiatric consequences of three overlapping types: mood disorder, post-traumatic stress disorder, and phobic anxiety about travel

- Among subjects with multiple injuries psychiatric complications are the greatest in those with severe disability; however, psychological complications are also frequent in those with whiplash neck injury

- Anxiety about travel as a driver and as a passenger is very common; in a fifth of subjects anxiety is persistent and disabling

- Post-traumatic symptoms are associated with having initial horrific memories, do not occur in subjects who are amnesic for the accident, and are not associated with past neurotic disposition

4 Breslau N, Davis GC. Post-traumatic stress disorder in an urban population of young adults: risk factor for chronicity. Am $\mathcal{F}$ Psychiatry 1992;149:671-5.

5 Breslau N, Davis GC, Peterson E. Traumatic events and post-traumatic stress disorder in an urban population of young adults. Arch Gen Psychiatry 1991;48:216-22.

6 Mayou RA, Simkin S, Threlfall J. Effects of road traffic accidents on driving behaviour. Injury 1991;22:365-8.

7 Cornes P. Return to work of road accident victims claiming compensation for personal injury. Injury 1992;23:256-60.

8 Newman PK Whiplash iniury BM7 1990;301:395.

9 Malt UF, Blikra G, Hoivik B. Bedre fore var. En studie i trafikkskader og deres folger. Nordbyhagen: Kirurgisk avdeling, Sentralsykehuset i Akershu

10 Feinstein A, Dolan R. Predictors of post-traumatic stress disorder following physical trauma: an examination of the stressor criterion. Psychol Med 1991;21:85-91.

11 Malt U. The long-term psychiatric consequences of accidental injury. Brf Psychiatry 1988;153:810-8.

12 Tunbridge RJ, Everest JT, Wild BR, Johnstone RA. An in-depth study of road accident casualties and their injury patterns. Crowthorne, Berkshire: Transport and Road Research Laboratory, 1988. (Digest of research report 136.)

13 Yates DW. Scoring systems for trauma. BMF 1990;301:1090-3.

14 Eysenck HJ, Eysenck SBE. Manual of the Eysenck personality inventory personality inventory. London: University of London Press, 1992.

personality inventory. London: University of London Press, 1992.
15 Beck AT. Depression inventory. Philadelphia: Center for Cognitive Therapy, 1978.

16 Spielberger $\mathrm{CD}$, Gorsuch R, Lushene R. State-trait anxiety inventory manual. Palo Alto: Consulting Psychologists Press, 1970.

17 Wing JK, Cooper JE, Sartorious N. Measurement and classification of psychiatric symptoms. Cambridge: Cambridge University Press, 1974

18 American Psychiatric Association. Diagnostic and statistical manual of mentol disorders, third edition, revised. Washington, DC: APS, 1987.

19 Krzanowski WJ. Principles of multivariate analysis: $a$ user's perspective. Oxford: Clarendon Press, 1988.

20 Everitt BS, Dunn G. Applied multivariate data analysis. London: Edward Arnold, 1991.

21 American Psychiatric Association. DSM-IV options book. Washington, DC APA, 1991.

22 World Health Organisation. The ICD-10 classification of mental and behavioural disorders. Geneva: World Health Organisation, 1992.

23 Davidson JRT, Foa EB. Post traumatic stress disorder. DSM-IV and beyond Washington, DC: American Psychiatric Press, 1992.

24 Davidson JRT, Foa EB. Diagnostic issues in post traumatic stress disorder considerations for the DSM-IV. F Abnorm Psychol 1991;100:346-55.

(Accepted 13 fuly 1993) 